\title{
El olvido de Armand Mattelart por la academia de comunicación mexicana
}

Javier Esteinou Madrid'

En la década de los años sesenta, en un clima académico de reinado del pensamiento funcionalista, especialmente del difusionismo norteamericano, llega Armand Mattelart a América Latina y trabaja intelectual y políticamente de forma intensa durante casi 23 años. A lo largo de su muy fecunda obra teórica, histórica, política y crítica Armand Mattelart produce más de 32 libros como autor y coautor y cientos de artículos especializados sobre los problemas centrales de la comunicación en América Latina, Europa y en el mundo en general.

Con la construcción de estos planteamientos conceptuales, Armand Mattelart introduce desde la década de los setenta una muy provocadora visión teórica, política y metodológica de la comunicación en casi todas las escuelas de comunicación, cultura, sociología, ciencias políticas, economía, educación, trabajo social, lingüística, etcétera, de México y América Latina, que dio origen a una nueva línea de análisis dentro de la sociología de la comunicación y la cultura. Con sus aportaciones teóricas produjo un parteaguas conceptual original que fermentó la conciencia de la comunicación en la academia latinoamericana y planteó otras preguntas e inquietudes políticas que generaron una revolución del conocimiento de la comunicación.

Armand Mattelart inicia sus trabajos de investigación y aportación teórica en el Centro de Demografía de la Universidad Católica de Chile, en Santiago de Chile, para continuar más adelante en el Centro de Estudios de la Realidad Nacional (CEREN) de la misma institución. Trabaja intensamente en Chile y posteriormente en Argentina, Cuba, México y los principales países de la región hasta 1973, cuando el golpe

1. Profesor-investigador, Departamento de Educación y Comunicación, Universidad Autónoma Metropolitana-Xochimilco. 
militar en contra del gobierno del presidente socialista chileno, Salvador Allende, lo obliga a salir abruptamente del país y buscar refugio en París, Francia.

Entre sus principales obras destacan Prefiguración de la ideología burguesa: lectura ideológica de una obra de Malthus (1975), Juventud chilena: rebeldía y conformismo (1970), Para leer al Pato Donald (1998c), Prensa y poder (1971), La ideología de la dominación en una sociedad dependiente (1972), Los medios de comunicación de masas. La ideología de la prensa liberal en Chile (1970c), La comunicación masiva en el proceso de liberación (1998a), Agresión desde el espacio(1998), La cultura como empresa multinacional (1994), Comunicación masiva y revolución socialista (1972a), Multinacionales y sistemas de comunicación (1997), Imperialismo y medios masivos de comunicación (1982), Cultura y comunicaciones de masa (1975a), Comunicación y transición al socialismo (1981a), Frentes culturales y movilización de masas (1977d), Mass media, idéologies et mouvement révolutionnaire (1974), Communication, and class struggle. Capitalism, imperialism (1979), El medio de comunicación de masas en la lucha de clases (1981b), Medios masivos y lucha de clases (1976), Medios de comunicación: mito burgués vs lucha de clases (1977), Los medios de comunicación en tiempos de crisis (1985a), América Latina en la encrucijada telemática (1983), Comunicación y nueva Hegemonia (1981), Cultura contra la democracia (1984b), Comunicación e ideologías de la seguridad (1985b), Televisión alternativa (1986), La comunicación como construcción de un mundo alternativo (1985), El carnaval de las imágenes. La ficción brasileña (1985c), Mercados internacionales de la imagen en búsqueda de una perspectiva alternativa (1984a), La publicidad (1991), La Internacional Publicitaria (1989), International image markets: in search of an alternative perspective (1984), Advertising internacional: the privatización of public space (1999), Tecnologia, cultura y comunicación (1988), La mundialización de la comunicación (1998b), Historia de las teorias de la comunicación (1995a), Pensar sobre los medios (1987), Technology, culture and communication: a report to the french minister of research and industry (1985d), La invención de la comunicación (1995), La comunicación mundo (1996), Historia de la utopia planetaria (2000), entre otros.

Entre sus principales artículos sobresalen "El medio de comunicación de masas en la lucha de clases" (1970b), "Los medios de comunicación de masas en un proceso revolucionario" (1971a), "La comunicación de la crisis" (1978), "Notas sobre el gremialismo y la línea de masas de la burguesía chilena" (1974b), "Los medios de comunicación masiva en una situación prerrevolucionaria" (1977b), "La 
industria cultural no es una industria ligera" (1973), "La industria Sésamo"(1973a), "El imperialismo en busca de la contrarevolución cultural" (1977a), "Multinacionales y sistemas de comunicación" (1978a), "Comunicación y cultura en América Latina" (1985e), "Hacia la formación de los aparatos ideológicos del Estado multinacional" (1981c), "Notas al margen del imperialismo cultural"(1982b), "Una cultura para administrar la crisis (1979a), "Plaza Sésamo y la coartada de la neutralidad" (1973b), "Otra ofensiva de las transnacionales: las nuevas tecnologías de comunicación"(1977c), "La institucionalidad de los estudios de comunicación"(1997a), "Los nuevos escenarios de la comunicación internacional" (1995b), "Construir la democracia" (1982a), "Against global inevitability" (1999a), y muchos más.

A través de sus múltiples reflexiones y búsquedas intelectuales durante más de tres décadas, Armand Mattelart examina en su pensamiento realidades como cultura y demografia,${ }^{2}$ juventud e ideología, ${ }^{3}$ comunicación y aparatos ideológicos, ${ }^{4}$ el imperialismo cultural, ${ }^{5}$ la cultura de masas y la economía de guerra, ${ }^{6}$ la monopolización creciente de la tecnología comunicativa, la agresión cultural, la industria del turismo en la reconversión del capitalismo, la economía política de la comunicación,? la ideología tecnocrática del imperialismo, el autoritarismo de la comunicación, la devolución del habla al pueblo, comunicación y democracia, ${ }^{8}$ la noticia como mercancía, el control de los medios, el hombre nuevo en la comunicación masiva, ${ }^{9}$ la civilización de la electrónica, la pentagonización de las comunicaciones, la liberalización del espacio, las multinacionales y la cultura, ${ }^{10}$ la democratización de la comunicación, ${ }^{11}$ la cultura en las guerras de liberación, ${ }^{12}$ los aparatos ideológicos de Estado

2. Armand Mattelart, iA dónde va el control de la natalidad?, Universitaria, Santiago de Chile, 1967; Le problématique du peuplement latinoaméricain, Editions Universitaires, París; Manual de análisis demográfico. Un ejemplo de investigación en un pais latinoamericano: Chile, Universidad Católica de Chile, Centro de Investigaciones Sociológicas, Centro para el Desarrollo Económico y Social de América latina, Santiago de Chile, 1968; La vivienda y los servicios comunitarios rurales: una metodologia de aproximación, Instituto de Capacitación e Investigación en Reforma Agraria, Santiago de Chile, 1968; Atlas social de las comunas en Chile, Pacifico, Santiago de Chile, 1965; Prefiguración de la ideologia burguesa: lectura ideológica de una obra de Malthus, Schapire, Buenos Aires, Argentina, 1975.

3. Juventud Chilena: Rebeldia y Conformismo, obra cit., pp. 1-60.

4. "Hacia la formación de los aparatos ideológicos del Estado multinacional", Revista Comunicación y Cultura, n. 4, obra cit.

5. Para leer al Pato Donald, obra cit., pp. 1-160.

6. "Multinacionales y Sistemas de Comunicación", Revista Nueva Sociedad, n. 38, obra cit., pp. 10-18.

7. La cultura como empresa multinacional, obra cit., pp. 108-147.

8. "Construir la Democracia", Revista Comunicación y Cultura, n. 7, obra cit.

9. Comunicación masiva y revolución socialista, obra cit., pp. 13-134.

10. Multinacionales y sistemas de comunicación, obra cit., pp 147-176.

11. Cultura y comunicaciones de masas, obra cit., pp. 90-154.

12. Comunicación y transición al socialismo, obra cit., pp. 11-67. 
y lucha de clases, ${ }^{13}$ la prensa y la lucha ideológica en los cordones industriales de Santiago de Chile, ${ }^{14}$ los medios en situaciones prerrevolucionarias, ${ }^{15}$ la comunicación en los estados de excepción, la internacionalización de la industria de la cultu$\mathrm{ra},{ }^{16}$ la geoestrategia de las redes, ${ }^{17}$ los medios-mundo, ${ }^{18}$ los nuevos paradigmas en la teoría de la comunicación, ${ }^{19}$ la privatización del consenso, ${ }^{20}$ el poder de la propagan$\mathrm{da},{ }^{21}$ la historia de las teorías de la comunicación, ${ }^{22}$ la desreglamentación de los flujos de información ${ }^{23}$, làs utopías de los vínculos de las redes, las tecnologías y las ciudades comunitarias, ${ }^{24}$ entre otros.

Su matriz epistemológica central parte de la necesidad indispensable de comprender los procesos de la comunicación desde fuera de la comunicación misma, para examinarla a partir del complejo de relaciones políticas, económicas, sociales, culturales, humanas, donde cobra vida, actúa y se determina. Es decir, para comprender la comunicación hay que olvidarse de ésta e interpretarla desde la cultura y los procesos de la reproducción social.

Si algo aportó la reflexión de Armand Mattelart para entender los procesos de cultura y de comunicación en América latina, fueron las bases de la economíapolítica para comprender la reproducción de dichos fenómenos en las sociedades contemporáneas y algunas vías para su transformación.

Apoyado en una metodología marxista de interpretación de los fenómenos sociales creó una nueva escuela de pensamiento crítico en la región que se convirtió en un eje epistemológico fundamental para analizar la comunicación latinoamerica-

13. Medios masivos y lucha de clases, obra cit., pp. 20-50; Medios de comunicación: mito burgués vs lucha de clases, obra cit., pp. 1-103 y 30-60.

14. Frentes culturales y movilización de masas, obra cit., pp. 9-45.

15. Los medios de comunicación masiva en una situación prerrevolucionaria, obra cit, pp. 1-4.

16. Comunicación y nueva hegemonia, obra cit., pp. 27-80.

17. Technology, culture and communication: A report to the French Minister of Research and Industry, obra cit., pp. 1-120.

18. La Internacional Publicitaria, obra cit., pp. 25-50 y 89-104; La mundialización de la comunicación, obra cit., pp. 9-13 y 81-90; "Los nuevos escenarios de la comunicación internacional", Revista Mexicana de Comunicación, n. 40, obra cit., y "Against global inevitability", Revista Media Development, n. 2, obra cit.

19. Pensar sobre los medios, obra cit., pp. 67-106.

20. América Latina en la encrucijada telemática, obra cit., pp. 17-37; Advertising international: The privatization of public space, obra cit., pp. 30-70.

21. La mundialización de la comunicación, obra cit., pp. 41-55.

22. La historia de las teorias de la comunicación, obra cit., pp. 9-139; "La Institucionalidad de los Estudios de Comunicación", Revista Telos, n. 49, obra cit.

23. La comunicación mundo. Historia de las ideas y de las estrategias, obra cit., pp. 240-269.

24. La invención de la comunicación, obra cit., pp. 113-145 y 170-205. 
na durante varios años. ${ }^{25}$ Así, por décadas emergieron diversas generaciones de jóvenes comunicadores que adoptaron su visión para comprender, trabajar y transformar de manera crítica los procesos de comunicación social en México y América Latina.

De esta forma surgió en las escuelas de comunicación latinoamericanas un nuevo dique conceptual crítico que colocó en el lugar limitado que le correspondían a las corrientes estructuralistas y funcionalistas, norteamericanas y europeas, que reinaban en los centros universitarios de la región, y sentó las bases teóricas para pensar desde la sociología y la economía política de la información diversas posibilidades que permitieran construir otros procesos de comunicación colectivos en nuestras sociedades. En síntesis, se puede decir que en el último tercio del siglo xx la obra de Armand Mattelart le proporcionó a México y América Latina otros ojos críticos para ver e imaginar la comunicación dentro de los procesos de reproducción y transformación social. Sin la aportación de Mattelart, la ceguera teórica e histórica del conocimiento totalizador de la comunicación colectiva hubiera continuado existiendo varias décadas más en América Latina.

\section{El olvido}

No obstante la trascendental e histórica aportación conceptual de Armand Mattelart para entender las claves del modelo de información dominante en México y América Latina y construir otros procesos culturales alternativos que permitan la sobrevivencia democrática de las naciones y el surgimiento de un nuevo ser humano, paradójicamente, a finales de la década de los años noventa, su pensamiento ha sido olvidado y desconocido por la mayoría de las escuelas de comunicación en México y en otras partes de América Latina. Esta situación ha llegado a tal extremo que en la actualidad, en México, 91 por ciento de los nuevos alumnos de las carreras de comunicación, al terminar de estudiar su profesión no saben quién es Armand Mattelart; 78 por ciento de los nuevos profesores actuales tampoco lo reconoce, $y$ los cursos y programas de estudio oficiales de la mayoría de las escuelas de comu-

25. Reconociendo las importantes aportaciones del pensamiento de Armand Mattelart para la formación de la corriente crítica de investigación de la comunicación en América Latina, el investigador boliviano Luis Ramiro Beltrán ha señalado que su análisis teórico contribuyó fundamentalmente a "desfetichizar los procesos y los medios de comunicación en la sociedad capitalista". Luis Ramiro Beltrán, Investigación sobre comunicación en Latinoamérica. Inicio, trascendencia y proyección, Universidad Católica Bolivariana, Plural, La Paz, agosto de 2000, pp. 52-53, 226-228, 266-267 y 279-280. 
nicación ya no incluyen en sus cursos su obra como referencia bibliográfica necesaria. ${ }^{26}$ Cuando más, sólo alguno de sus últimos textos es incluido tardíamente en programas especializados de información, como los posgrados o diplomados. Es decir, es una acumulación conceptual que espontáneamente ya no se discute, ni še toma como referente central para asimilar y cambiar los tiempos culturales de las postrimerías del siglo $\mathrm{xx}$.

Un estudio realizado sobre una muestra de 120 alumnos y 60 profesores de las carreras de Comunicación de la Universidad Autónoma Metropolitana, Unidad Xochimilco (UAM-X), la Universidad Iberoamericana (UIA), la Universidad Intercontinental (UIC), el Instituto Tecnológico de Estudios Superiores de Monterrey (ITESM), la Universidad del Valle de México (UVM) y la Universidad Nacional Autónoma de México (UNAM), en la Ciudad de México, en abril y mayo del 2000; reflejó que 91 por ciento de los alumnos de las escuelas de comunicación, que están a punto de terminar sus estudios, no saben quién es Armand Mattelart y sólo 9 por ciento lo conoce (Gráfica 1).

\section{GRÁFICA 1}

Población de estudiantes de las escuelas de comunicación mexicanas que conocen a Armand Mattelart

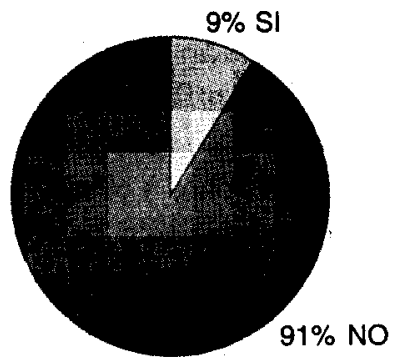

26. "El Impacto del Pensamiento de Armand Mattelart en la Academia de la Comunicación Mexicana", Encuesta realizada a los estudiantes y profesores de las carreras de comunicación de la Universidad Autónoma Metropolitana, Unidad Xochimilco (UAM-x), la Universidad Iberoamericana (UIA), la Universidad Intercontinental (UIC), el Instituto Tecnológico de Estudios Superiores de Monterrey (ITESM), la Universidad del Valle de México (UVM) y la Universidad Nacional Autónoma de México (UNAM), en la Ciudad de México, en abril y mayo del 2000. La muestra total fue de 120 alumnos (20 por cada institución) y 60 profesores ( 10 por cada institución) de las seis universidades mencionadas. Las preguntas para alumnos fueron las siguientes: a) ¿Sabes quién es Armand Mattelart? b) ¿Cuál es el principal libro que conoces de Armand Mattelart? c) ¿Cuál es el último libro que has leído de Armand Mattelart? d) ¿Cuál es la mayor aportación que te ha dado el pensamiento de Armand Mattelart para comprender los problemas de la comunicación de México y América Latina? Las 
De ese 9 por ciento de estudiantes que sí lo reconoce, 33 por ciento confirma que el libro que más conoce de Armand Mattelart es Para leer al Pato Donald, 13 por ciento La Comunicación Mundo, 4 por ciento Pensar sobre los medios, 4 por ciento Historias de las teorias de la comunicación y el 46 por ciento restante no recuerda el nombre de sus libros (Gráfica 2).

\section{GRÁFICA 2}

¿Cuáles son los libros de Armand Mattelart más reconocidos por los estudiantes de las escuelas de comunicación?

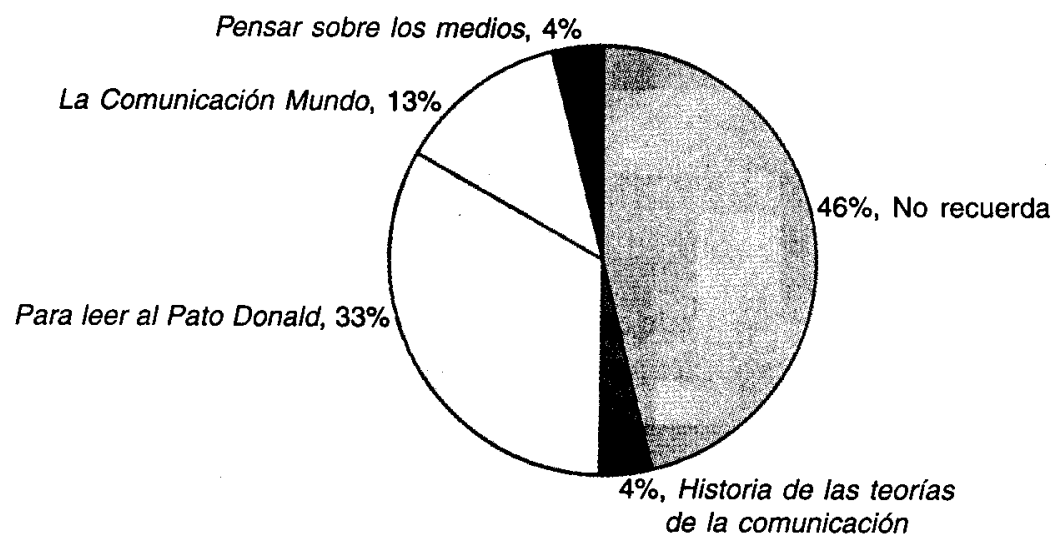

Del 9 por ciento que sí lo ubica, 32 por ciento responde que el último libro que ha leído de Armand Mattelart es Para leer al Pato Donald, 8 por ciento La comunicación mundo, 8 por ciento Historias de las teorías de la comunicación, 4 por ciento Multinacionales y sistemas de comunicación, 4 por ciento Pensar sobre los medios y el 44 por ciento no recuerda cuál es el último libro que leyó (Gráfica 3).

preguntas para profesores, fueron las siguientes: a) ¿Sabes quién es Armand Mattelart? b) ¿Cuál es el principal libro que conoces de Armand Mattelart? c) ¿Cuál es el último libro que has leído de Armand Mattelart? d) ¿Cuál es la mayor aportación que te ha dado el pensamiento de Armand Mattelart para comprender los problemas de la comunicación de México y América Latina? e) ¿En qué cursos incluyes la bibliografia de Armand Mattelart? 


\section{GRÁFICA 3}

¿Cuál es el último libro de Armand Mattelart leído

por los estudiantes de las escuelas de comunicación?

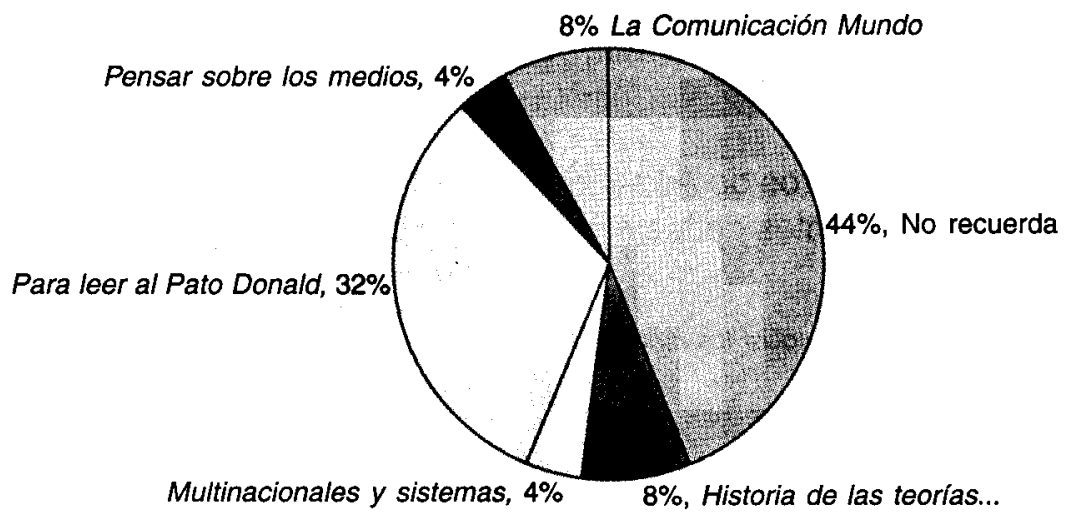

Finalmente, ese 9 por ciento de estudiantes que sí lo conoce dan testimonio que las principales aportaciones que les proporcionó el pensamiento de Armand Mattelart, son las siguientes:

- Entender la comunicación como un fenómeno complejo.

- Comprender la relación entre imperialismo y medios de difusión.

- Conocer otras posiciones críticas ante las teorías tradicionales de la información.

- Analizar la reestructuración de la comunicación de manera global.

- Examinar el papel de los medios en el proceso de reproducción social.

- Descubrir los vínculos entre economía, política y comunicación.

- Examinar la homogenización cultural de las sociedades por la acción de los mass media.

- Conocer nuevos modelos de comunicación alternativa.

- Entender la dependencia cultural del pensamiento comunicacional latinoamericano en la década de los setenta de las escuelas norteamericanas de comunicación.

Por otra parte, 78 por ciento de los profesores actuales de las universidades mexicanas estudiadas tampoco reconoce quién es Armand Mattelart, y sólo 22 por ciento ubica quién es (Gráfica 4). 


\section{GRÁFICA 4}

Población de profesores de las escuelas de comunicación mexicanas que conocen a Armand Mattelart

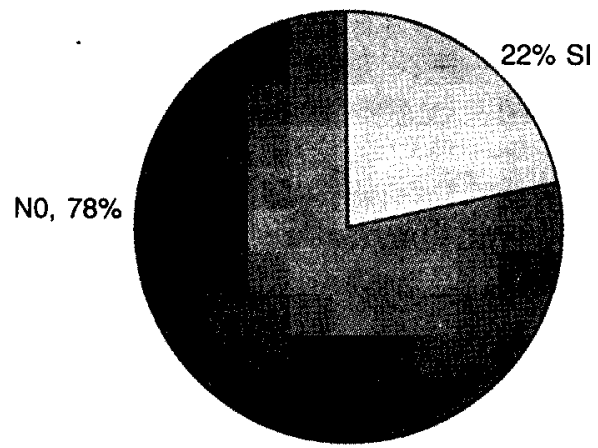

De ese 22 por ciento de profesores que sí lo reconoce, 55 por ciento designaron Para leer al Pato Donald como el principal libro de ese autor, 16 por ciento a Historias de las teorías de la comunicación, 12 por ciento a Comunicación mundo, 5 por ciento a Pensar los medios, 2 por ciento a La cultura como empresa multinacional, 2 por ciento a América Latina en la encrucijada telemática, 2 por ciento a La comunicación masiva en el proceso de liberación y el 2 por ciento restante no recuerda (Gráfica 5).

\section{GRÁFICA 5}

¿Cuáles son los libros de Armand Mattelart más reconocidos por los profesores de las escuelas de comunicación?

La cultura como empresa... $2 \%$

Historia de las teorias... $16 \%$

América Latina en... 2\%

Pensar los medios, 5\%

La comunicación masiva... $2 \%$

Comunicación mundo, $12 \%$

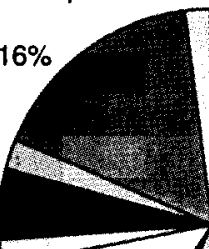

No recuerda, $2 \%$

55\%, Para leer al Pato Donald 
De esa población ( 22 por ciento de docentes que sí lo ubica), 41 por ciento señala que el último libro que ha leído de Armand Mattelart es La comunicación mundo, 30 por ciento Historias de las teorias de la comunicación, 8 por ciento Pensar sobre los medios, 7 por ciento Para leer al Pato Donald, 6 por ciento La cultura como empresa multinacional, 2 por ciento América Latina en la encrucijada telemática, 2 por ciento La comunicación masiva en el proceso de liberación y el 4 por ciento restante no recuerda (Gráfica 6).

\section{GRÁFICA 6}

¿Cuál es el último libro de Armand Mattelart leido por los profesores de las escuelas de comunicación?

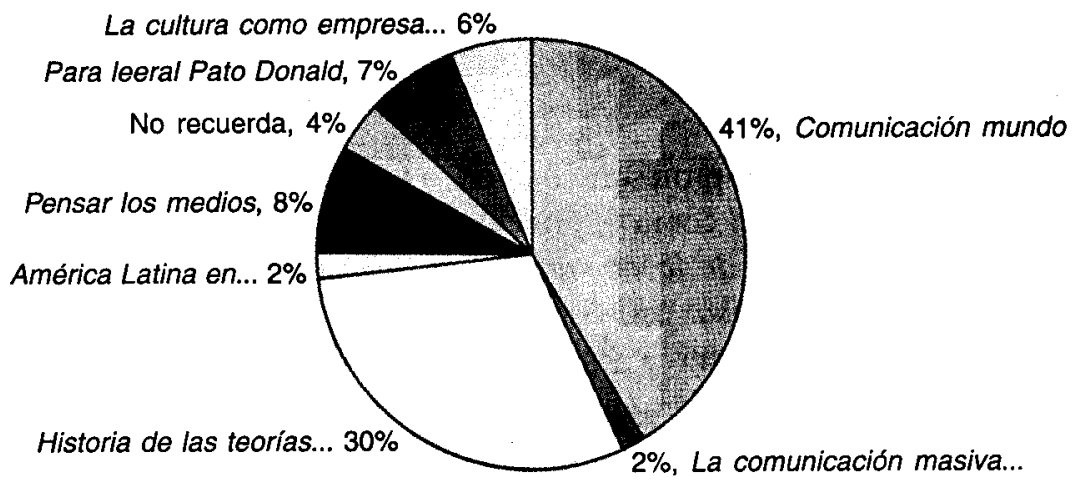

De ese 22 por ciento de profesores que sí leen a Armand Mattelart, 52 por ciento incluye sus textos en los cursos de licenciatura, 8 por ciento en maestría, 5 por ciento en doctorado y el 35 por ciento no lo considera (Gráfica 7).

Finalmente, ese 22 por ciento de docentes que sí lo conocen certifica que las principales aportaciones del pensamiento de Armand Mattelart, son las siguientes:

- Entender a las industrias culturales como aparatos ideológicos.

- Comprender la relación entre cultura de masas y economía de guerra.

- Revelar los procesos autoritarios de la comunicación.

- Diferenciar críticamente las diversas teorías de la comunicación.

- Establecer las vinculaciones entre globalización y procesos de comunicación.

- Conocer la dinámica creciente de la monopolización de la tecnología comunicativa. 
- Analizar la comunicación como mercancía.

- Descubrir los nuevos mecanismos de la desregulación informativa.

- Entender la dependencia cultural que se forma a través de los medios de información.

\section{GRÁFICA 7}

¿En qué niveles de enseñanza de las escuelas de comunicación son incluidos los libros de Armand Mattelart?

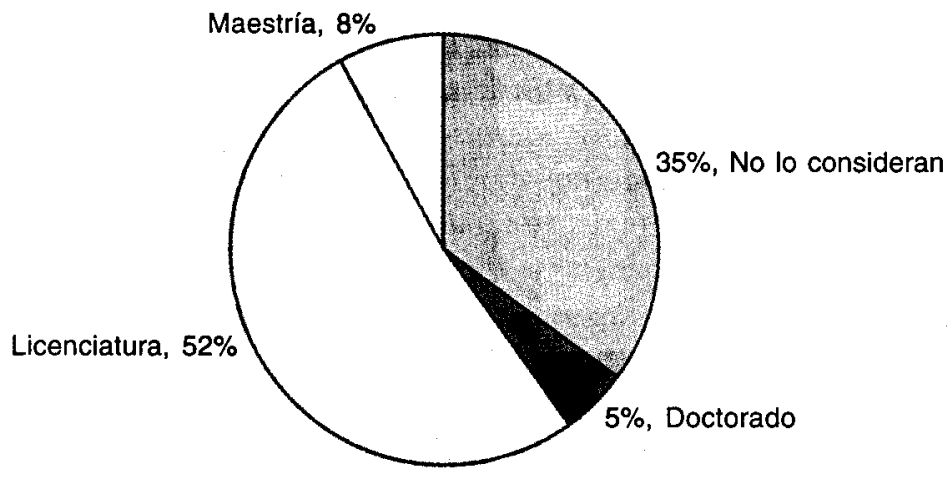

Es por eso que ahora, 30 años después de la aportación de esta gran semilla intelectual al pensamiento comunicacional mexicano y latinoamericano, es necesario preguntarnos $¿ Q$ Qué ha sucedido en la academia mexicana y latinoamericana que ha colocado en el olvido y en el desconocimiento la gran contribución intelectual de Armand Mattelart para entender la era informativa y cultural del nuevo siglo?

\section{Las razones}

Ante esta realidad podemos decir que desde la década de los setenta Armand Mattelart aportó una gran riqueza teórica y política para hacer avanzar el pensamiento comunicacional en América Latina y que dicho fenómeno de amnesia académica se ha originado por las causas que a continuación se detallan. 


\section{Modernidad vs. pasado}

Desde el momento en que los centros de estudio de la comunicación mexicana y latinoamericana han sido atravesados por las leyes de la modernidad globalizadora, especialmente tecnológica, han asimilado los principios de que lo avanzado es lo reciente y lo inmediato; y no lo pasado. Así, el movimiento de la modernidad ha acentúado la contradicción existente entre lo tradicional y lo moderno en el campo de la cultura y la información. No debemos olvidar que uno de los ejes de construcción y valoración de lo moderno es lo que aparece como nuevo y actual, y no lo que figura como viejo.

En este sentido, se observa que "lo nuevo es uno de los aspectos centrales y de culto del proceso de la modernidad, y no dejar de serlo - al contrario, se agudizaen los actuales momentos tanto posmodernos como neoliberales. Antes y hoy estar al día. O ser moderno o posmoderno, significaba y significa tener y/o conocer lo nuevo, término que cada vez aparece en todo, desde anuncios y etiquetas comerciales hasta en temáticas de encuentros y eventos científicos. Dicha tendencia se ha acentuado tanto, que ha logrado que lo nuevo tenga menos duración y pronto, muy pronto, se convierta en antiguo y obsoleto". ${ }^{27}$

La aplicación de esta tendencia cultural al interior de la academia de la comunicación, ha contribuido a plantear que el pensamiento de Armand Mattelart es anacrónico simplemente por pertenecer al pasado y no al presente. Así, sin haber examinado el desarrollo y la estructura conceptual del pensamiento crítico de Armand Mattelart, la academia mexicana y latinoamericana gradualmente lo han olvidado y marginado, señalando infantilmente que ya está "superado" por pertenecer al pasado. Por consiguiente, sin conocer dicha construcción teórica, asombrosamente la actual "modernidad intelectual" de la comunicación latinoamericana ha olvidado paulatinamente la riqueza de la obra de Armand Mattelart.

\section{Cultura básica vs cultura parasitaria}

Los gigantescos torrentes de información cotidiana que produce la carrera de la modernidad a través de los medios de difusión colectivos y las nuevas tecnologías de información, han ocasionado una grave dificultad para diferenciar lo sustancial de lo accesorio y trazar jerarquías para conservar lo fundamental. Esto ha gene-

27. Enrique Guinsberg, "Los Estudios e Investigaciones en Comunicación en Nuestros Tiempos Neoliberales y Posmodernos", Universidad Autónoma Metropolitana, Unidad Xochimilco, Documento fotocopiado, México, febrero de 2001, p. 2. 
rado en la academia la presencia de un mundo de información parasitaria que ha contribuido a revolver y sepultar los conocimientos sustanciales para substituirlos por concepciones pragmáticas superficiales o de moda, de muy corto plazo.

Esto significa, que a finales de la década de los noventas, la enseñanza de la comunicación mantiene un fuerte sesgo del conocimiento que privilegia el desarrollo de las modas informativas o el tecnologisismo espectacular y no el rescate de la herencia del pensamiento crítico profundo. Es el caso de las contribuciones muy relevantes de Mattelart que han quedado ahogadas por un mar de información light o tercearia que sólo sobreviven con apuntalamientos de estrategias de marketing coyuntural y que han obstaculizado el reconocimiento del pensamiento profundo al producir inmensas cantidades de basura intelectual.

Sobre ello, hay que tener en cuenta que "el mundo light siempre ha existido pero nunca alcanzó las magnitudes presentes en un desarrollo que permite ver su imparable crecimiento a niveles todavía mayores. Ahora todo tiende a ser leve y liviano, pero ya no visto como criticable o superficial, sino como valioso, digno y necesario, como un avance de lo moderno que permite estar y vivir mejor o con menos problemas. Lo light aparece en todo, y muchas veces con títulos y anuncios que lo destacan: en alimentos y bebidas, en literatura (los llamados best sellers, pero no en los títulos que alcanzan gran difusión y tienen calidad, sino en la hecha intencionalmente con tal fin, dominante en publicaciones periódicas), en la programación radial, televisiva y cinematográfica, que es absolutamente dominante, etcétera". ${ }^{28}$

Así, la cultura de finales del siglo xx e inicios del xxI se ha caracterizado por tener rasgos fuertemente lights que llevan a la "búsqueda de la liviandad, el hedonismo epidérmico, la vida del aqui y ahora, las seducciones inmediatas sin mucha importancia por el futuro, el sumergirse en experiencias sensoriales de todo tipo, la velocidad y rapidez para encarar todo, la obtención de efectos concretos, rápidos y con el menor esfuerzo posible, etcétera". ${ }^{29}$ Toda esta atmósfera cultural posmoderna que también ha permeado a los centros de formación y pensamiento comunicacional, ha contribuido sustancialmente al olvido de las aportaciones conceptuales de A. Mattelart.

\section{El abandono de las raíces del conocimiento crítico}

La caída del Muro de Berlín y el desmembramiento de los países socialistas de la Unión de Repúblicas Socialistas Soviéticas (URSs), propició a nivel internacional un

28. Enrique Guinsberg, "Lo light, lo domesticado y lo bizantino en nuestro mundo psi", Revista Subjetividad y Cultura, n. 14, Plaza y Valdés, México, abril de 2000, p. 9.

29. Ibid, pp. 10-11. 
clima intelectual acrítico de descalificación a priori del marxismo como corriente de pensamiento y de práctica política en el mundo contemporáneo. Esto contribuyó en México y América Latina a que, sin haberse discutido el pensamiento de Armand Mattelart, silenciosamente se le haya substituido, y en algunos casos, sin haberlo conocido, banalmente se haya descalificado, argumentando que está atravesado por una epistemología marxista anacrónica de interpretación de las realidades comunicativas que no es útil para los fines de la modernidad. En este sentido, es importante subrayar que "múltiples artículos, investigaciones y publicaciones indican que esta postura crítica es cada vez menor, mientras se extiende un conjunto de estudios e investigaciones con tendencias tecnocráticas, pragmáticas, de descontextualización de la parte respecto al todo, acríticas respecto a los marcos políticos e ideológicos predominantes, que vuelan por diferentes galaxias teóricas sin nunca aterrizar en la realidades que dicen analizar o investigar, o despolitizadas de manera explícita o con una idea de política que conduce a la abstracción estéril o queda en un discurso lleno de palabras pero vacío de contenido". ${ }^{30}$

Es por ello, que hay que considerar que, en términos generales, con la implantación del neoliberalismo no se ha dado el auge de proyectos de cambio, sino todo lo contrario: se han producido múltiples variantes de posturas genéricamente conocidas como posmodernas en el campo intelectual-cultural; crisis y decadencia de proyectos rebeldes, revolucionarios o alternativos; crecimiento de posturas conservadoras clásicas o aggiornadas de la nueva derecha; crisis de paradigmas y de utopías en todos los terrenos, etcétera.

En tal contexto, ha cambiado rotundamente el rol o papel del intelectual, que de fiscal o crítico, hoy predominantemente, con notorias e importantes excepciones, ha perdido tal condición para adecuarse e incluso defender las leyes (implícitas o explícitas) de la competencia, rendimiento, adecuación, etcétera, de una economía de mercado que no respeta ni le interesan las críticas y cuestionamientos de fondo por parte de quienes viven bajo su cobijo y subsidios (estatales o privados).

Nunca como ahora ha predominado tanto el pensamiento unidimensional tal como lúcidamente lo describió Marcuse, sea por tal disminución de la crítica cuestionante, como porque una mayoría de la que hay (y se difunde) se ubica en terrenos esterilizantes, deshistorizados e inocuos del peor de los discursos posmodernos de moda. ${ }^{31}$

Dentro de este marco histórico se constata una tendencia "donde pareciera que el intelectual crítico ha perdido el papel clásico que ha tenido siempre en la historia,

30. Enrique Guinsberg, op. cit., p. 2.

31. Enrique Guinsberg, op. cit., p. 8. 
para convertirse, salvo excepciones, en integrados o con una postura sólo supuestamente crítica". ${ }^{32}$

Así, debido a estas dinámicas ideológicas, sin haberse examinado la obra intelectual de Armand Mattelart irresponsablemente se le ha sepultado en el silencio del pasado, sin que se haya precisado si podía seguir soportando epistemológicamente la prueba de la realidad o del transcurso del tiempo.

\section{El imperio del conocimiento pragmático}

Debido al cultivo de la "tendencia altamente mercantilista y pragmática que ha caracterizado el desarrollo de la estructura cultural del modelo neoliberal en México y América Latina desde la década de los ochenta, se ha acentuado la dinámica de desproteger e incluso hacer desaparecer la investigación de la comunicación de carácter humanista y social; y se ha impulsado desmedidamente desde las políticas oficiales científicas y educativas de los Estados nacionales latinoamericanos los estudios marcadamente tecnológicos, pragmáticos y eficientistas de la información". ${ }^{33}$

En este sentido, por ejemplo:

han surgido intensamente en la región las investigaciones sobre las características fisicas de las nuevas tecnologías de información, la ampliación de la televisión directa, la introducción de internet, la expansión de los satélites, el empleo de las nuevas computadoras, el estudio de las intertextualidades, el examen del ciberespacio, la interacción de las máquinas de información de la última generación, el examen de la adaptación de los medios virtuales, la comunicación organizacional, la reflexión sobre la interconectividad, etcétera; y se ha descuidado u olvidado drásticamente el análisis elemental de los procesos de democratización de los medios de comunicación, el empleo de las nuevas tecnologías para impulsar el desarrollo social, el uso de las infraestructuras informativas para defender la ecología, el empleo de los medios para producir alimentos, el aprovechamiento de dichas tecnologías para reducir la violencia, el uso de la comunicación para la rehumanización de las ciudades, la utilización de los recursos comunicativos para la conservación de las cacienas biológicas de manutención de la vida, su uso para la defensa de los derechos humanos, la reutilización de las estructuras de comunicación para crear

32. Guinsberg, op. cit., 2001, p. 4.

33. Javier Esteinou Madrid, "La evolución de la teoría e investigación de la comunicación en México y América Latina, Revista Espacios de Comunicación, n.3, Departamento de Comunicación, Universidad Iberoamericana, México, 1998, p. 240. 
culturas básicas para la sobrevivencia social, su aprovechamiento para el rescate de las culturas indígenas, la reutilización de estos avances tecnológicos para el incremento de la participación social, etcétera. ${ }^{34}$

En este sentido, se nota que "el campo de estudio e investigación de la comunicación en muy importante medida ha caído en tal seducción, y si bien difícilmente alguien niegue algo de lo anterior — salvo los defensores de la hoy hegemónica economía de mercado-, es evidente que la primacía de las preocupaciones se ubican en los terrenos de lo nuevo, al punto que en múltiples reuniones y encuentros estas problemáticas simplemente están ausentes como si no existieran, fueran cosas del pasado o temas viejos. ${ }^{35}$ De esta forma, podemos decir que en las instituciones de enseñanza de la información "las problemáticas humanistas, éticas o filosóficas de la investigación de la comunicación crecientemente se han deslegitimizado para dar lugar a las temáticas que parten de los intereses de la razón instrumental o pragmática. Hoy vivimos un reencantamiento intelectual por los temas de investigación que fija las necesidades de la Mano Invisible del Mercado", ${ }^{36}$

Por este motivo, "poco a poco, ha ido tomando fuerza una mirada, que aparentando ser independiente de la del Norte de EuA, es en el fondo un remedo de lo que en el Norte se considera investigación avanzada. Ahí donde América Latina puso lo mejor y más original de su esfuerzo en los años setenta y ochenta - lo que implicó la búsqueda de un nuevo Orden Informativo Internacional-, hoy está siendo minado. En este contexto, la investigación opta por salvarse haciendo que tome un rumbo, cada vez, más pragmático, menos inquietante, menos abierto, inspirándose en la demanda y no en la sociedad... Están ganando aquellos que para Adorno sólo hacian investigación administrativa, que es la que se despliega hoy a través de la comunicación organizacional, empresarial e incluso de buena parte del llamado periodismo de investigación. ${ }^{37}$

34. Javier Esteinou Madrid, "La investigación de la comunicación en los tiempos neoliberales", Revista Telos n. 47, Cuademos de Comunicación, Tecnología y Sociedad, Fundación para el Desarrollo Social de las Comunicaciones (fundesco), Madrid, Septiembre-Noviembre de 1996, pp. 16-18.

35. Enrique Guinsberg, op. cit., 2001, p. 4.

36. Javier Esteinou Madrid, "La investigación de la comunicación en los tiempos neoliberales", Revista Electrónica Razón y Palabra n.11, Año 3, (Primera Revista Electrónica en América Latina), Departamento de Comunicación, Instituto Tecnológico de Estudios Superiores de Monterrey, Campus Estado de México (ITESM), México, Julio-Septiembre de 1998.

37. Martha Renero Quintanar, "Una mirada al campo de la comunicación. Conversación con Jesús Martín Barbero", Revista Comunicación y Sociedad, n. 34, Universidad de Guadalajara, Guadalajara, México, 1998; citado por Enrique Guinsberg en "Los estudios e investigaciones en comunicación en nuestros tiempos neoliberales y posmodernos", op. cit., p. 5. 


\section{Así, con el}

lugar estratégico que el nuevo modelo de desarrollo modernizador le ha concedido al mercado para ser el eje fundamental que dirija y modele a los procesos sociales y educativos en México y América Latina, éste se ha convertido en el condicionante y el disparador central del cual se han derivado el origen, el sentido y el destino de la producción cultural y comunicativa en nuestros países, especialmente de la investigación de la comunicación. Es decir, dentro del reciente patrón de crecimiento neoliberal que ha asumido América latina, la verdadera reactivación del proyecto de investigación social de la comunicación de las culturas nacionales no ha resurgido de la antiquísima demanda de los grupos sociales básicos por resolver las necesidades sociales más apremiantes de la población para sobrevivir y reforzar sus identidades locales; sino que se ha derivado de la incorporación acelerada de nuestras sociedades al mercado mundial, que no es otra realidad que la reactivación y la ampliación intensiva del proyecto económico super transnacional en la periferia. ${ }^{38}$

Esta marcada tendencia cultural ha contribuido sustancialmente a que el pensamiento crítico de Armand Mattelart no sea valorado como un conocimiento útil para la consolidación de las necesidades del modelo de comunicación de mercado, y en consecuencia sea retirado de las principales discusiones contemporáneas en el campo de la comunicación, para ser substituido por el boom de las concepciones y acciones pragmáticas.

\section{El taylorismo epistemológico}

Para fortalecer la tendencia fuertemente pragmática que ha invadido el campo de la producción de conocimiento en comunicación, se ha generado un taylorismo epistemológico, que formula que para ser más eficientes y competitivos en dicho terreno se debe crear una gran separación especializada en la operación y la producción del conocimiento. Así, en el campo de las ciencias sociales ha surgido "una práctica que apunta a una superespecialización en la división del trabajo, ya no sólo entre, sino al interior de las ciencias sociales". ${ }^{39}$

Dicha superespecialización de las tareas informativas ha hecho que los grandes planteamientos conceptuales para explicar la realidad, como es el pensamiento de

38. "La evolución de la teoría e investigación de la comunicación en México y América Latina", Obra cit., p. 241.

39. Guillermo Peimbert, "El taylorismo en las ciencias sociales. La artificial e innecesaria fragmentación del desarrollo científico en México", La Jornada, México, 8 de enero de 2001. 
Armand Mattelart, no sean vistos como relevantes para resolver los problemas de la comunicación contemporánea, sino que sea la vertiente del conocimiento muy dividido el que, cada vez mas, se demande como conocimiento avanzado. Ante ello, debemos tener presente que de continuarse esta tendencia los trabajadores de la comunicación tendremos ojos para ver lo más sofisticado, pero no lo más elemental.

\section{El conocimiento como mercancía}

La presión de la dinámica del mercado sobre la cultura ha propiciado que en las escuelas de comunicación el conocimiento especializado se adquiera como una mercancía más que se usa provisionalmente y se desecha como moda cuando aparece otra más novedosa y atractiva; y no como el conjunto de conocimientos que permite conocer y resolver los problemas presentes. Es decir, hoy día existe una gran inclinación intelectual donde el estudio de la comunicación vale más por su fachada que por su contenido. La forma substituye a la esencia.

En este sentido, parece que el conocimiento que se acepta y reproduce en los centros de enseñanza proviene de la dinámica que marcan los intereses del mercado y no por la reflexión científica de la disciplina de la comunicación. Esta tendencia ha desechado no sólo el pensamiento de A. Mattelart de las escuelas de información mexicanas y latinoamericanas, sino también la de otros pensadores muy relevantes para el conocimiento de la comunicación como son el de Herbert Marcuse, ${ }^{40}$ Paulo Freire, ${ }^{41}$ Nicos Poulantzas, ${ }^{42}$ Antonio Gramsci ${ }^{43}$ y, de continuar esta orientación, es muy probable que en pocos años se deseche a importantes pensadores contemporáneos como Jesús Marín Barbero y Jürgen Habermas.

40. Herbert Marcuse, El hombre unidimensional, Planeta, México, 1985.

41. Paulo Freire, La Educación Como Práctica de la libertad, Siglo xxı, México, 1972; Pedagogía del oprimido, Siglo xxı, México, 1973.

42. Nicos Poulantzas, Poder Politico y Clases Sociales en Estado Capitalista, Editorial Siglo xxi, México, D.F., 1969; Estado, poder y socialismo, Siglo xxI, México, 1979; Fascismo y dictadura, Siglo xxi, México, 1971; Critica de la hegemonia de Estado, Cuervo, Buenos Aires, 1976; Las clases sociales en el capitalismo actual, Siglo xxI, México, 1976 y "La crisis de los partidos", en Le Monde Diplomatique (En español), septiembre de 1979.

43. Antonio Gramsci, La formación de los intelectuales, Grijalbo, México, 1972; La opinión pública, Pasado y Presente, Granica, Buenos Aires, 1974; "Notas sobre Maquiavelo, sobre la política y sobre el Estado moderno", Obras de Antonio Gramsci, Tomo I, Juan Pablo, México, 1975; "Problemas escolares y la organización de la cultura", Obras de Antonio Gramsci, Tomo II, Juan Pablos, México, 1975 y El materialismo histórico y la filosofia de Benedetto Croce, Nueva Visión, Buenos Aires, 1976. 
Otro factor que, desprendido de las lógicas anteriores, también ha influido en esta marginación teórica, aunque en menor grado, es el hecho de que las investigaciones que por encargo han contratado las empresas de información o el Estado con las escuelas de comunicación, prioritariamente han demandado la producción de conocimiento rápido y muy pragmático que contribuya a fortalecer el status quo del actual sistema social y no a cuestionarlo para transformarlo. Así, prolifera en las universidades "la investigación experta al servicio de la demanda empresarial que privilegia el desarrollo de estos estudios y no los del conocimiento crítico, cuya misión debería ser construir una mirada distanciada frente al pragmatismo managerial; lo que de ninguna manera implica aislarse de estas nuevas realidades, sino al contrario, se trata de plantearlas como problemáticas". ${ }^{44}$

Por lo tanto, esta tendencia de investigación ha desplazado el empleo de la reflexión crítica del pensamiento de Mattelart, al no considerarlo fundamental para las necesidades de la modernidad.

\section{La anarquía cultural}

La aplicación de la dinámica de la Mano Invisible del mercado sobre los procesos de comunicación y cultura ha generado en América Latina un fuerte desorden informativo, que ha producido silenciosamente una anarquía cultural al permitir que estemos altamente informados sobre lo secundario y no sobre lo fundamental. Esta anarquía cultural, acelerada por la dinámica del mercado, ha creado un caos en la conciencia colectiva, ocasionando que la energía social se concentre en los procesọ de la super acumulación material y ha impedido que resolvamos como sociedad los grandes problemas nacionales que nos impiden crecer en nuestras naciones.

Derivada de esta lógica desde la década de los ochenta, ha surgido gradualmente en la atmósfera mental de México y América Latina una cultura idiota que se caracteriza por construir una visión de la vida altamente fragmentada, descontextualizada y superficial que se produce con los enormes y rápidos torrentes de información secundaria o terciaria que transmiten los medios de información sobre nuestros sentidos. Dicha cultura, amparada en la tesis de la libertad de co-

44. Enrique Guinsberg, op. cit., 2001, p. 6. 
municación, nos ha llevado a saber cada vez más del gran mundo externo y cada día menos de nosotros como naciones, comunidades y como personas. ${ }^{45}$

$\mathrm{Su}$ modelo se caracteriza por promover en grandes dimensiones la difusión intensiva de la información secundaria, la violencia temática, el consumo exacerbado, la invasión de la privacía, la banalización de la realidad, la comunicación alarmante, morbosa y sensacionalista, la imposición mental del principio de la ganancia a toda costa, la frivolidad informativa, el entretenimiento vulgar y estrafalario, la cosmovisión hollywodense de la vida, etcétera, con tal de obtener raitings y vender; en detrimento de la calidad de los contenidos y de la necesidades orgánicas de comunicar los mensajes estratégicos que requerimos asimilar colectivamente como pueblos y civilización latinoamericana para transformar nuestra conciencia y poder sobrevivir en el continente.

De esta forma, la modernidad mexicana y latinoamericana de mercado ha planteado que en la fase de apertura de libre comercio "la basura informativa tiene libertad para circular en los medios de difusión", ${ }^{46}$ y la consecuencia de abdicar de la construcción de una cultura para la sobrevivencia humana al iniciar el siglo XXI, vía los canales de información, es el triunfo de la cultura idiota en México y América Latina. En este sentido, podemos pensar que debido a que la nueva forma de financiamiento que plantea el modelo neoliberal lleva a que los medios gubernamentales se comercialicen más, y por lo tanto sean los patrocinadores quienes determinen el contenido de transmisión de los canales, cada vez ha sido más difícil promover una cultura de desarrollo social donde, pues el esquema de sostenimiento de dichas empresas ha buscado crecientemente la obtención de la máxima ganancia monetaria a corto plazo.

Dicha cultura idiota no sólo ha penetrado las estructuras de los medios de comunicación, sino también en las escuelas de información, desplazando los conocimientos teóricos más amplios que permiten analizar y transformar la realidad. Uno de los teóricos más importantes que ha sido enterrado por la expansión de la lógica de la cultura idiota en México, ha sido el pensamiento de Mattelart.

45. Javier Esteinou Madrid, "Siglo xxI, leyes del mercado y nuevo proyecto de comunicación en America Latina", xvin Encuentro Académico: La Comunicación Frente al Desarrollo Humano y Social: Balance y Perspectivas, Corporación Universitaria Minuto de Dios (UMD), Facultad de Comunicación Social y Periodismo, Santa Fe de Bogotá, Colombia, 30 de agosto al $1^{\circ}$ de septiembre del 2000.

46. “La Cultura Idiota", Carl Bernstein, Revista Nexos n. 177, México, septiembre de 1992. 


\section{El olvido de Armand Mattelart}

El conjunto de estas realidades ha provocado que los profesores e investigadores de las escuelas de comunicación no discutan ya la obra conceptual de Mattelart, y en consecuencia no la incluyan como bibliografia básica en sus cursos profesionales. No obstante que, en esencia, el contenido conceptual del pensamiento Mattelarniano sigue siendo válido para la actualidad, su lugar teórico ha sido ocupado por el pragmatismo eficientista de la fase de la globalización.

\section{El desconocimiento del legado teórico de Mattelart}

Derivado de estos factores, las nuevas generaciones de estudiantes de las instituciones de comunicación no conocen la obra de A. Mattelart, pues sus maestros no la leen, no la recomiendan, y mucho menos la incluyen en sus cursos profesionales para discutir y reflexionar.

\section{Las escuelas de comunicación y el ciclo de la frivolidad}

Este panorama demuestra, una vez más, que al final del siglo $\mathrm{xx}$ el común denominador de las estructuras de conocimiento que se reproduce en las escuelas de comunicación mexicanas y latinoamericanas, responde a reacciones de coyuntura, a modas intelectuales o a las frivolidades culturales que ha introducido el glamour de la modernidad; no corresponden a un sólido trabajo de revisión y reflexión sobre la evolución del pensamiento latinoamericano en el campo de la comunicación, que permita generar una síntesis sobre la herencia conceptual que han aportado las concepciones críticas y, con ello, rescatar muchos elementos de conocimiento altamente valiosos para resolver los actuales conflictos comunicativos de nuestra región.

Esta realidad refleja que con la introducción de las lógicas de la modernidad a las escuelas de comunicación mexicanas se ha acelerado el proceso de pérdida de memoria de dichas instituciones, y ahora éstas viven una profunda amnesia intelectual que ha llevado a privilegiar lo superfluo por lo fundamental; el espectáculo por sobre el pensamiento profundo; el ciberespacio tecnotrónico por sobre la comunicación participativa; la evasión de la realidad por sobre el incremento de nuestros niveles de conciencia; la reflexión inmediatista por sobre la mentalidad para la sobrevivencia; la priorización de la información de una cultura del show por encima 
de una dinámica de la comunicación sustentable, la democracia electrónica por sobre la comunicación democrática; la economía política de la comunicación por la comunicología, etcétera. ${ }^{47}$ Para que se acepte el modelo del pensamiento profundo en las escuelas de comunicación debe estar basado en el show, el espectáculo o la cultura efectivista y no en el simple rigor del conocimiento científico.

Ante ello, debemos preguntarnos: ¿Qué clase de memoria colectiva están reproduciendo las escuelas de comunicación en México y América Latina, si con el vértigo de la modernidad estas instituciones viven un proceso acelerado de pérdida de memoria histórica?, ¿qué clase de forma de ver la vida están reproduciendo las escuelas de comunicación, si no cuentan con memoria histórica?

\section{La amnesia cultural}

Esta amnesia y miopía comunicacional no sólo se produce en las escuelas de comunicación de América Latina, sino también en los partidos políticos y en la sociedad civil, que tampoco han recuperado el arsenal teórico, histórico, filosófico y político del pensamiento de Armand Mattelart que contribuye a resolver las problemáticas ideológicas contemporáneas que les toca enfrentar.

\section{La cultura de la información y la pérdida de la sabiduría}

De esta forma, podemos decir que la cultura formada durante tantos años en la academia de la comunicación en México y América Latina, cada vez más, es una cultura de la información y no de la sabiduría. ${ }^{48}$ En este sentido, en las últimas décadas, las escuelas de comunicación latinoamericanas han ido perdiendo la sabiduría para quedarse solamente con las tecnologías y la información: Lo que hemos perdido en el camino es la diferencia existente entre el saber y el conocer. ${ }^{49}$

47. Para ampliar este punto véase Esteinou Madrid, "La investigación de la comunicación en los tiempos neoliberales", op. cit., pp. 16-18.

48. Para ampliar este punto consultar, Esteinou Madrid, “Internacionalización, Cultura, Dinámica de Mercado y Cambio de Conciencia Humana", Memorias Académicas: Diez Años de Comunicación Social y Periodismo 1986-1996, División de Comunicación Social, Corporación Autónoma de Occidente (CuAu), Cali, Colombia, diciembre de 1996, pp. 33-72.

49. Coberos, Jaime, "Presentación al Libro Esperando el milenio, Reflexiones sobre el final de los tiempos, D. Bonet, J. Coberos, L. M. Martinez Otero, J. Perasejordi y J. Phaure, II Semana de Estudios sobre el Pensamiento Heterodoxo de San Sebastián, Ediciones 29, Barcelona, p. 10. 


\section{El abandono del hombre}

Ante este panorama, podemos decir que "para el modelo central de comunicación que hemos construido en los últimos años en las escuelas de comunicación en México y América Latina todo ha sido importante considerar, excepto nosotros como seres humanos. Es decir, nosotros no hemos sido importantes para nosotros mismos, pues no hemos colocado al fenómeno humano en el centro de la reflexión, la discusión y la acción comunicativa; nos hemos enredado en el tratamiento y la super valoración de las mediaciones tecnológicas más sofisticadas, situándolas como el fin último del quehacer profesional comunicativo y no como meros apoyos materiales para alcanzar otras metas superiores. En algunos casos, cuando los individuos han estado como centro de reflexión de la comunicación, no ha sido con el fin de ser concebidos como seres humanos que tienen necesidad de desarrollarse como personas, sino como meros consumidores de productos y servicios que requiere movilizar el modelo de acumulación para lograr sus ganancias. Esto es, el sujeto de nuestra comunicación ha sido el manejo de las técnicas informativas para la realización del capital y no la transformación de los seres humanos". ${ }^{50}$

Tal parece que al olvidar las aportaciones del pensamiento de Armand Mattelart y otros teóricos críticos básicos, "el proyecto de comunicación moderna que con toda energía nos hemos esforzado por construir en los últimos años en México y América Latina, se ha fundado mayoritariamente sobre la negación misma del proceso de comunicación interna del hombre. Es decir, da.la impresión de que la relación de la comunicación que los especialistas en esta disciplina hoy producimos entre los individuos, no es aquélla que permite que los hombres nos conozcamos y profundicemos más en nosotros mismos y en el núcleo social que los rodea; sino que al contrario, es un mecanismo ajeno impuesto desde afuera de la inferioridad más central del hombre, que lo que genera es la oscuridad de los seres". ${ }^{51}$

Por ello, podemos afirmar que "la relación que hemos construido con nosotros mismos y con la sociedad a través de la comunicación, especialmente urbana, nos ha llevado a un estado generalizado de incomunicación, y por lo tanto de pérdida de nosotros mismos como personas, como familia, como barrio, como comunidad, como

50. Javier Esteinou Madrid, "El periodismo cultural en los tiempos de las grandes ciudades", Revista Electrónica n.10, El Diálogo de la Comunicación, Año 3, (Primera Revista Electrónica en América Latina), Departamento de Comunicación, Instituto Tecnológico de Estudios Superiores de Monterrey, Campus Estado de México (ITESM), México, D.F., Abril-Junio de 1998, p. 23; "La ciudad como proceso de comunicación, Revista Interacción n. 9, Revista de Comunicación Educativa, Centro de Comunicación Educativa Audiovisual (CEDAL), Santa Fe de Bogotá, Colombia, Febrero-Marzo de 1996, p. 20.

51. Ibid, 21. 
región, como país y como memoria. Esto es, la comunicación que hoy practicamos es un mero artificio más sobre la superficie de la sociedad y de nuestras existencias, pues no va al fondo de las necesidades profundas del hombre. Es una dinámica eminentemente informativa para la consolidación del sistema económico y no comunicativa para el desarrollo humano".52

Ante esta realidad, "nos preguntamos ¿para qué queremos las máquinas de difusión de la quinta generación y los trillones de bits de información que nos ofrece la modernidad, si hoy en las urbes entre los seres humanos nos es progresivamente más dificil comunicarnos de mirada a mirada, de corazón a corazón, de centro a centro? Por ello, podemos afirmar que el saldo gremial que queda después de 70 años de estudio y práctica especializada de la comunicación en América Latina, es que hoy hemos perdido lo más importante por lo meramente secundario y accesorio. Es por ello que, al iniciar el siglo XXI, podemos decir que nuestra sociedad cuenta con especialistas técnicos, médicos, químicos, administradores, ingenieros, abogados, políticos, etcétera; pero en estricto sentido, no obstante que existimos miles de individuos especializados en el campo de la comunicación, las sociedades latinoamericanas todavía no poseen verdaderos comunicadores. Esto, debido a que dichos cuadros profesionales nos dedicamos a ejercer todas las actividades propias del quehacer informativo, excepto construir las condiciones para que los seres humanos se conozcan a sí mismos, se encuentren, se aproximen, se humanicen y evolucionen hacia etapas superiores del Ser". ${ }^{33}$

Ante ello, debemos cuestionarnos ¿Qué tan central para nuestros problemas sociales de comunicación es el conocimiento que estamos produciendo en las escuelas de información en México?

Sin embargo, y a pesar del olvido sistemático del pensamiento de Armand Mattelart por las escuelas de comunicación, su semilla intelectual sigue viva latentemente y resurge en cualquier momento, cuando su pensamiento vuelve a exponerse en las escenas universitarias. Muestra de ello ha sido el gran poder de convocatoria académica que ha obtenido en sus últimas participaciones en el seminario sobre "el Futuro de la Lengua Castellana", en Guanajuato, México, 1996; ${ }^{54}$ el seminario sobre "Los Desafios de la Comunicación Globalizada", en Lima, Perú, 1997.55 el coloquio sobre Comunicación y Sociedad, en San Cristóbal de Las Casas, Chiapas, México,

52. Ibid, 22.

53. Ibid

54. "El Futuro de la Lengua Castellana", Simposium Internacional, Consejo Nacional para la Cultura y las Artes (CNCA), Secretaría de Educación Pública (SEP) y Gobiemo de Guanajuato, México, 1996.

55. "Desafios de la comunicación globalizada", ix Encuentro Latinoamericano de Facultades de Comunicación Social, Federación Latinoamericana de Facultades de Comunicación Social (FELAFAcs) y Universidad de Lima, Lima, Perú, 27 al 31 de Octubre de 1997. 
1997; ${ }^{56}$ el Diálogo sobre Comunicación, Cultura y Fin de Siglo, en Mérida, Yucatán, México, 1999; ${ }^{57}$ el curso sobrc Comunicación y Modernidad en el Doctorado en Comunicación Social de la Facultad de Ciencias Antropológicas de la Universidad Autónoma de Yucatán, en Mérida, México, julio del $2000^{58}$ y la calurosa bienvenida recibida en el Magister en Comunicación, en la Universidad Diego Portales y la Asociación Chilena de Investigadores de la Comunicación en Chile, noviembre del 2000. ${ }^{59}$

De aquí la enorme importancia estratégica al final del milenio por efectuar un profundo alto intelectual en la vertiginosa dinámica cultural de la modernidad mexicana y latinoamericana que nos lleva a correr, correr y correr sin saber hacia dónde vamos, para rescatar las bases del pensamiento crítico de nuestros antecesores y repensar desde las condiciones elementales de la conservación de nuestras vidas cuáles son las prioridades en el campo de la comunicación que debemos investigar y practicar para sobrevivir como sociedades independientes, democráticas, sabias, sustentables y humanas en México y América Latina.

Con ello, colocaremos bases más sólidas para crear otro proyecto de comunicación, de cultura y de espiritualidad regional que partan de las necesidades elementales de crecimiento y humanización de los hombres, y no de los simples requerimientos dominantes de la voraz y salvaje acumulación económica planetaria, a costa de lo que sea.

\section{Referencias bibliográficas de Armand Mattelat}

(1965), Atlas social de las comunas en Chile, Pacífico, Santiago de Chile. (1967), ¿A dónde va el control de la natalidad?, Universitaria, Santiago de Chile.

(1968), La vivienda y los servicios comunitarios rurales: una metodología de aproximación, Instituto de Capacitación e Investigación en Reforma Agraria, Santiago de Chile.

56. "Comunicación y Sociedad", Encuentro Internacional, Universidad Nacional Autónoma de México (UNaM), San Cristóbal de Las Casas, Chiapas, México, 1997.

57. "Comunicación, cultura y fin de milenio", Dirección General de Desarrollo Académico, Sub Dirección de Extensión, Universidad Autónoma de Yucatán, Mérida, México, 8 al 13 de septiembre de 1999.

58. "La elección democrática, equiparable al levantamiento zapatista: Mattelart, Revista Proceso No. 1239, México, 30 de julio del 2000, pp. 75-76.

59. "Los Mattelart de regreso a Chile, discuten los caminos de la Escuela Latinoamericana de Comunicación", Revista del Pensamiento Comunicacional Latinoamericano, n. 2, vol. 2, Revista Cientifica Digital (PCLo), Cátedra unesco de Comunicaçao, Universidad Metodista de Sao Paulo y Asociación Latinoamericana de Investigadores de la Comunicación (ALAIC), Sao Paulo, Brasil, eneromarzo del 2001. Citado en http://www.metodista.br/unesco/PCLA/index.htm 
(1968a), Manual de análisis demográfico. Un ejemplo de investigación en un país latinoamericano: Chile, Universidad Católica de Chile, Centro de Investigaciones Sociológicas, Centro para el Desarrollo Económico y Social de América Latina, Santiago de Chile.

(1970), Juventud chilena: rebeldia y conformismo, Editorial Universitaria, Santiago de Chile.

(1970a), Le problématique du peuplement latinoaméricain, Editions Universitaires, Paris.

(1970b), "Los medios de comunicación de masas en la lucha de clases, en Revista Cine cubano n. 69 y 70, La Habana.

Michèle Mattelart y Mabel Piccini (1970c), Los medios de comunicación de masas. La ideología de la prensa liberal en Chile, Cuadernos de la realidad Nacional n. 3, Edición Especial, Centro de Estudios de la Realidad Nacional (CEREN), Universidad Católica de Chile, Santiago de Chile.

(1971), Prensa y poder. Chile: la prensa de izquierda y el poder popular. Argentina: la prensa de derecha y el poder burgués, ISAL, MISUR, Santiago de Chile.

(1971a), "Los medios de comunicación de masas en un proceso revolucionario", en revista Los Libros, Buenos Aires, enero-febrero.

Carlos Castillo y Leonardo Castillo (1972), La ideología de la dominación en una sociedad dependiente, Signos, Buenos Aires.

Patricio Biedma y Santiago Funes (1972a), Comunicación masiva y revolución socialista, Diógenes, México.

(1973), "La industria cultural no es una industria ligera", en Revista Casa de las Américas n. 77, vol. XII, La Habana, marzo-abril.

(1973a), "La industria Sésamo", en Revista Mexicana de Ciencias Politicas, n. 74, año XIX, Nueva Epoca, Facultad de Ciencias Políticas y Sociales, Universidad Nacional Autónoma de México, México, octubre-diciembre.

Michèle Mattelart (1973b), "Plaza Sésamo y la coartada de la neutralidad", en: Revista Siempre! n. 1038, México.

(1974), Mass media, idéologies et mouvement révolutionnarie, Anthropos, París. (1974b), "Notas sobre el gremialismo y la línea de masas de la burguesía chilena", en Chile vencerá, varios autores, Roca, México.

(1975), Prefiguración de la ideología burguesa: lectura ideológica de una obra de Malthus, Schapire, Buenos Aires.

M. A. Garretón, H. Valdés, L. Domínguez, C. Ossa, Ariel Dorfman y C. Maldonado 
(1975a), Cultura y comunicaciones de masa. Materiales de la discusión chilena (1970-1973), Laia, Barcelona.

(1976), Medios masivos y lucha de clases, Causachún, Lima.

(1977), Medios de comunicación: mito burgués vs lucha de clases, Aquelare, Bogotá.

(1977a), "El imperialismo en busca de la contrarevolución cultural, en Revista Comunicación y Cultura n. 1, Departamento de Educación y Comunicación, Universidad Autónoma Metropolitana, Unidad Xochimilco, México.

(1977b), "Los medios de comunicación masiva en una situación prerrevolucionaria",

Revista Arte, sociedad e ideología n. 2, México, agosto-septiembre.

$(1977 \mathrm{c})$, "Otra ofensiva de las transnacionales: las nuevas tecnologías de comunicación", en La información en el nuevo orden internacional, Instituto Latinoamericano de Estudios Transnacionales (ILET), México.

Michèle Mattelart (1977d), Frentes culturales y movilización de masas, Anagrama, Colección de Elementos Críticos, Barcelona.

(1978), "La comunicación de la crisis", Primer Encuentro Latinoamericano sobre la Enseñanza de la Comunicación, Carrera de Comunicación Social, Departamento de Educación y Comunicación, Universidad Autónoma Metropolitana, Unidad Xochimilco, México.

(1978a), "Multinacionales y sistemas de comunicación", Revista Nueva Sociedad, n. 38, Paraguay.

Seth Siegelaub (1979), Communication, and class struggle. Capitalism, imperialism, vol. 1, International Mass Media Research Center, New York.

(1979a), Michèle Mattelart, "Una cultura para administrar la crisis", en Le Monde Diplomatique, n. 10 (en español), Año 1, México.

(1981), Comunicación y nueva hegemonia, Editorial Comisión Evangélica Latinoamericana de Educación Cristiana (CELADS), República Dominicana.

(1981a), Comunicación y transición al socialismo: el caso Mozambique, Era, México.

(1981b), El medio de comunicación de masas en la lucha de clases, Serie Situaciones n. 17, Universidad Autónoma de Sinaloa, México.

(1981c), "Hacia la formación de los aparatos ideológicos del Estado multinacional,

Revista Comunicación y Cultura n. 4, Departamento de Comunicación, Universidad Autónoma Metropolitana, Unidad Xochimilco, México.

Ariel Dorfman, V. Erhart y Teodoro Adorno (1982), Imperialismo y medios masivos de comunicación, Ediciones Quinto Sol, México.

(1982a), "Construir la democracia", Revista Comunicación y Cultura n. 7 Depar- 
tamento de Comunicación, Universidad Autónoma Metropolitana, Unidad Xochimilco, México.

(1982b), "Notas al margen del imperialismo cultural", Revista Comunicación y cultura n. 6, Departamento de Comunicación, Universidad Autónoma Metropolitana, Xochimilco, México.

Héctor Schmucler (1983), América Latina en la encrucijada telemática, Paidós, Buenos Aires.

(1984), International image markets: in search of an alternative perspective, Comedia Publishing Group, Londres.

Michèle Mattelart y Delcout X, (1984a), Mercados internacionales de la imagen en búsqueda de una perspectiva alternativa, Comedia, Londres, Inglaterra. Xavier Delcourt y Michèle Mattelart (1984b), ¿La cultura contra la democracia?

Lo audiovisual en la época transnacional, Mitre, Barcelona.

(1985), La comunicación como construcción de un mundo Alternativo, Universidad Nacional Autónoma de México, México.

(1985a), Los medios de comunicación en tiempos de crisis, Siglo XXI, México. Michèle Mattelart (1985b), Comunicación e ideologias de la seguridad, Anagrama, Barcelona.

Michèle Mattelart (1985c), El carnaval de las imágenes. La ficción brasileña, Akal, Brasil.

Michèle Mattelart (1985d), Technology, culture and communication: A report to the French Minister of Research and Industry, North Holland, Amsterdam. (1985e), "Comunicación y cultura en América Latina", Revista Contiene, n. 13, SEP, UAM, México, marzo.

Jean Marie Piemme (1986), Televisión alternativa, Anagrama, Barcelona.

Michèle Mattelart (1987), Pensar sobre los medios, Fundesco, Madrid.

Y. Stouidze (1988), Tecnologia, cultura y comunicación, Colección Nuevo Siglo, Mitre, Barcelona.

(1989), La Internacional Publicitaria, FUNDEsco, Madrid.

(1991), La publicidad, Paidós, Barcelona.

(1994), La cultura como empresa multinacional, Era, México.

(1995), La invención de la comunicación, Siglo xxi, México.

Michèle Mattelart (1995a), Historia de las teorias de la comunicación, Paidós, Buenos Aires.

(1995b), "Los nuevos escenarios de la comunicación internacional", Revista Mexicana de Comunicación, n. 40, Año 7, Fundación Manuel Buendía, México, mayo-julio. 
(1996), La comunicación mundo. Historia de las ideas y de las estrategias, Siglo XXI, México.

(1997), Multinacionales y sistemas de comunicación, Siglo xxI, México.

(1997a), "La institucionalidad de los estudios de comunicación", Revista Telos, n. 49, Cuadernos de Tecnología y Sociedad, Madrid.

(1998), Agresión desde el espacio. Cultura y Napalm en la era de los satélites,

Siglo xxi (12a Edición), México.

(1998a), La comunicación masiva en el proceso de liberación, Siglo xxI (14a Edición), México.

(1998b), La mundialización de la comunicación, Paidós, Barcelona.

Ariel Dorfman (1998c) Para leer al Pato Donald, Siglo xxI (34a Edición), México. (1999), Advertising international: The privatization of public space, Routledge,

Londres.

(1999a), “Against global inevitability”, Revista Media Development, n. 2, Inglaterra. (2000), Historia de la utopía planetaria, Paidós, Buenos Aires.

(2000a), "La elección democrática, equiparable al levantamiento zapatista:

Mattelart”, Revista Proceso, n. 1239, México, 30 de julio.

\section{Bibliografía}

Beltrán, Luis Ramiro, Investigación sobre comunicación en latinoamérica. Inicio, trascendencia y proyección, Universidad Católica Bolivariana, Plural, La Paz, agosto del 2000.

Bernstein, Carl, "La cultura idiota", Revista Nexos, n. 177, México, septiembre de 1992. Coberos, Jaime, "Presentación al Libro Esperando el milenio. Reflexiones sobre el final de los tiempos", D., Bonet, J., Coberos, L. M. Martínez, Otero, J. Perasejordi y J. Phaure, II Semana de Estudios Sobre el Pensamiento Heterodoxo de San Sebastián, Ediciones 29, Barcelona, España.

Consejo Nacional para la Cultura y las Artes (CNCA), Secretaría de Educación Pública (SEP) y Gobierno de Guanajuato, El futuro de la lengua castellana, Simposium Internacional, México, 1996.

Dirección General de Desarrollo Académico, Sub Dirección de Extensión, Universidad Autónoma de Yucatán, Mérida, Comunicación, cultura y fin de milenio, México, 8 al 13 de septiembre de 1999. 
"El Impacto del Pensamiento de Armand Mattelart en la Academia de la Comunicación Mexicana", Encuesta realizada a los estudiantes y profesores de las carreras de Comunicación de la Universidad Autónoma Metropolitana, Unidad Xochimilco (UAM-X), la Universidad Iberoamericana (UIA), la Universidad Intercontinental (UIC), el Instituto Tecnológico de Estudios Superiores de Monterrey (ITESM) y la Universidad Nacional Autónoma de México (UNAM), en México, D.F., en mayo y junio del 2000.

Esteinou Madrid, Javier, "El periodismo cultural en los tiempos de las grandes ciudades", Revista Electrónica No.10, El diálogo de la comunicación, Año 3, Revista Electrónica Vía internet, Primera Revista Electrónica en América Latina, Departamento de Comunicación, Instituto Tecnológico de Estudios Superiores de Monterrey, Campus Estado de México (ITESM), México, Abril-Junio de 1998.

—, "Internacionalización, cultura, dinámica de mercado y cambio de conciencia humana", Memorias Académicas: Diez Años de Comunicación Social y Periodismo 1986-1996, División de Comunicación Social, Corporación Autónoma de Occidente (CUAU), Cali, Colombia, diciembre de 1996.

—, "La ciudad como proceso de comunicación", Revista Interacción n. 9, Revista de Comunicación Educativa, Centro de Comunicación Educativa Audiovisual (CEDAL), Santa Fe de Bogotá, Colombia, febrero-marzo de 1996.

—, "La investigación de la comunicación en los tiempos neoliberales", Revista Telos n.47, Cuadernos de Comunicación, Tecnología y Sociedad, Fundación para el Desarrollo Social de las Comunicaciones (FUNDESCO), Madrid, septiembre-noviembre de 1996, pp. 16-18.

-, "Siglo xxI, leyes del mercado y nuevo proyecto de comunicación en America Latina", xviII Encuentro Académico: La Comunicación frente al desarrollo humano y social: balance y perspectivas, Corporación Universitaria Minuto de Dios (UMD), Facultad de Comunicación Social y Periodismo, Santa Fe de Bogotá, Colombia, 30 de agosto al 1 de septiembre de 2000.

, "La investigación de la comunicación en los tiempos neoliberales", Revista Electrónica Razón y palabra n.11, Año 3, Primera revista electrónica en América Latina, Departamento de Comunicación, Instituto Tecnológico de Estudios Superiores de Monterrey, Campus Estado de México (ITESM), México, julio-septiembre de 1998.

, "La evolución de la teoría e investigación de la comunicación en México y América Latina", Revista Espacios de comunicación n. 3, Departamento de Comunicación, Universidad Iberoamericana, México, 1998. 
Freire, Paulo, La educación como práctica de la libertad, 1972 y Pedagogía del oprimido, 1973, Siglo xxI, México.

Gramsci, Antonio, La formación de los intelectuales, Grijalbo, México, 1972.

__, El materialismo histórico y la filosofía de Benedetto Croce, Nueva Visión, Buenos Aires, 1976.

—, La opinión pública, Pasado y Presente, Granica, Buenos Aires, 1974.

__ , "Notas sobre Maquiavelo, sobre la política y sobre el Estado moderno", "Problemas escolares y la organización de la cultura" Obras de Antonio Gramsci, Tomos I y II, Juan Pablos, México, 1975.

Federación Latinoamericana de Facultades de Comunicación Social (FELAFACS) y Universidad de Lima, Desafios de la comunicación globalizada, Ix Encuentro Latinoamericano de Facultades de Comunicación Social, 27 al 31 de octubre de 1997.

Guinsberg, Enrique, "Lo light, lo domesticado y lo bizantino en nuestro mundo psi”, Revista Subjetividad y Cultura n. 14, Plaza y Valdés, México, 2000.

$\longrightarrow$, Los estudios e investigaciones en comunicación en nuestros tiempos neoliberales y posmodernos", Universidad Autónoma Metropolitana, Unidad Xochimilco (Documento fotocopiado), México, febrero de 2001.

Marcuse, Herbert, El hombre unidimensional, Editorial Planeta, México, D.F., 1985. Peimbert, Guillermo; "El taylorismo en las ciencias sociales. La artificial e innecesaria fragmentación del desarrollo científico en México", La Jornada, México, 8 de enero de 2001.

Poulantzas, Nicos, Estado, poder y socialismo, Siglo xxI, México, 1979.

—, Critica de la hegemonía de Estado, Cuervo, Buenos Aires, 1976.

—., Fascismo y dictadura, Siglo xxI, México, 1971.

-, "La crisis de los partidos", en Le Monde Diplomatique (En español), septiembre de 1979.

_- Las clases sociales en el capitalismo actual, Siglo XXI, México, 1976.

- Poder politico y clases sociales en Estado capitalista, Siglo XXI, México, 1969.

Renero Quintanar, Martha, "Una mirada al campo de la comunicación. Conversación con Jesús Martín Barbero", Revista Comunicación y Sociedad, n. 34, Universidad de Guadalajara, Guadalajara, México, 1998.

Revista del Pensamiento Comunicacional Latinoamericano, n. 2, v. 2, Revista Científica Digital (PCLO), Cátedra UNESCo de Comunicaçao, Universidad Metodista de Sao Paulo y Asociación Latinoamericana de Investigadores de la Comunica- 
ción (ALAIC), "Los Mattelart de regreso a Chile, discuten los caminos de la Escuela Latinoamericana de Comunicación", Sao Paulo, Brasil, enero-marzo, 2001. Citado en http://www.metodista.br/unesco/PCLA/index.htm

Universidad Nacional Autónoma de México, Comunicación y sociedad, Encuentro Internacional, San Cristóbal de Las Casas, Chiapas, México, 1997. 